\title{
Design and Validation of Performance Evaluation Model of National Accreditation Schemes in Hospitals: A Mixed-Method Study
}

\author{
Seyyed Payam Paymard ${ }^{1}$, Leila Najafi ${ }^{2,}$ and Israfil Roshdi ${ }^{3}$ \\ ${ }^{1} \mathrm{PhD}$ Candidate in Health Services Management, Department of Health Services Management, Faculty of Medical Sciences, Semnan Branch, Islamic Azad \\ University, Semnan, Iran \\ ${ }^{2}$ Assistant Professor, Department of Health Services Management, Faculty of Medical Sciences, Semnan Branch, Islamic Azad University, Semnan, Iran \\ ${ }^{3}$ Assistant Professor, Department of Basic Sciences, Semnan Branch, Islamic Azad University, Semnan, Iran
}

* Corresponding author: Leila Najafi, Department of Health Services Management, Faculty of Medical Sciences, Semnan Branch, Islamic Azad University, Semnan, Iran.

Received 2020 December 19; Revised 2021 June 07; Accepted 2021 June 26.

\begin{abstract}
Background: Performance evaluation of accreditation schemes can improve the quality of hospital accreditation significantly. An effective accreditation system is one that performs the accreditation process properly and achieves acceptable results.

Objectives: This study aimed to design and validate the performance evaluation model of national accreditation schemes in hospitals. Methods: This study was performed in a mixed method. The performance evaluation dimensions of the national accreditation models for hospitals were identified, classified, and modeled using the qualitative research method. The quantitative aspect of the obtained model was tested using structural equation modeling.

Results: All identified variables were classified into six dimensions including causal conditions, strategic conditions, axial phenomenon, context conditions, intermediary/interventional conditions, and consequence. The results of the quantitative part suggested that the proposed model had a good fit and its validity and reliability were confirmed.

Conclusion: The results of the present study revealed that the performance evaluation model of national accreditation schemes in hospitals had a good fit and might be used as an effective model in accreditation organizations as a roadmap to better evaluate accreditation schemes, such as those used in hospitals.

Keywords: Accreditation model, Combined study, Hospital, Validation
\end{abstract}

\section{Background}

Hospitals play an important role in maintaining the mental and physical health of people. However, the quality of the services they provide should be in line with customers' expectations. Therefore, maintaining the quality of hospital services requires a comprehensive system for planning, improvement, and evaluation (1). Hospital accreditation is a process that leads to quality assurance, safety, effectiveness, and efficiency of hospital services (2).

Some studies have emphasized that accreditation is a good strategy to increase the quality and safety of health services, reduce medical errors and hospital mortality, and improve hospital performance (3). Therefore, most health care managers and policymakers in the field of health, standardization, accreditation, and evaluation of health service providers consider it inevitable to improve quality (4). The role of accreditation and certification in improving patient and organizational outcomes is largely unclear. Accreditation and certification is a thriving industry, and many interested stakeholders benefit from upgrading these services despite the lack of strong evidence regarding their effectiveness (5).

Although accreditation improves the performance of hospitals $(6,7)$, there are criticisms against the evaluation criteria of hospitals, including the focus of accreditation standards on the structural aspects and ignoring the outcomes and effectiveness of treatments, as well as the evaluators' lack of impartiality. Sack et al. questioned the impact of accreditation on provided services. They believed that the impact of accreditation will be revealed over time and it is not possible to determine a point in time for the impact of accreditation (8). According to the research, there are many limitations in using valid tools for data collection as well as accreditation evaluation methods (9-10). Some researchers have suggested that the accreditation models may not be able to properly evaluate hospitals and that the results may not be reliable (11-12).

Despite hospital accreditation standards and grading schemes, many hospitals still lack adequate quality and efficiency (13).

The results of the study conducted by Salmon et al. (14) and Greenfield et al. (15) showed that accreditation is a process that helps improve performance and develop positive outcomes in patients. The results of the study carried out by Arab et al. (16) showed that not only patients are not well aware of their rights, but their rights are also not properly respected by medical centers. They stated that the adoption of a comprehensive law and the design of a specific program to monitor and supervise the implementation of the law is necessary to ensure 
the observance of patients' rights.

\section{Objectives}

Regarding the fact that the results of the studies do not show a documented relationship between the results of national accreditation schemes and the quality of hospital services, the present study aimed to propose and validate a performance evaluation model of national accreditation schemes for hospitals to measure the quality of hospital services.

\section{Methods}

A combined research method has been adopted for the present study. The use of a combined method help accelerate the achievement of research goals and provides a more complete picture and deeper understanding of the studied phenomena. Due to the use of the paradigm model in designing the model and the lack of specific studies in direct connection to the research topic, it is not possible to rely on previous sources. On the other hand, many variables affecting the validation of hospitals have interaction in such a way that it is not acceptable to focus on some and control or manipulate other variables. In an attempt to study the considered phenomena in a real way the qualitative research method and the grounded theory have been selected based on constructivist-interpretive approaches. Grounded theory is a method that aims to recognize and understand people's experiences of events in a specific context. In the quantitative part, the study is a descriptive survey in terms of data collection and cross-sectional in terms of time horizon.

In the qualitative part of the research, according to the reliance of grounded theory on the ideas and experiences of experts and interviewees, the statistical population includes managers and staff experts, and national evaluators of hospitals, and senior and middle managers of the first pole of the country (i.e., Mazandaran, Gilan, Semnan, and Golestan provinces). They were selected purposively and studied through semi-structured interviews. Sampling continued until data saturation so that the selection of a new sample did not provide distinctive information to the researcher. In this study, information saturation was obtained with a total of 16 experts.

The statistical population in the quantitative sector is composed of managers and staff experts, national evaluators of a hospital accreditation scheme, senior and middle managers of hospitals, providers, and recipients of health care services in educational and medical centers of the first pole of the country $(n=460)$. Based on Cochran's formula (with 95\% confidence interval and measurement error of 0.05), 210 people were selected as a statistical sample using multi-stage random clustering. The researcher-made questionnaires (whose validity and reliability was confirmed) were distributed normally and electronically with the cooperation of the administrative department of educational and medical centers.

The systematic data-based approach was used as the method of analysis in the qualitative part of the study, which has been discussed in the joint works of Strauss and Corbin. The data analysis was performed during three main stages of open coding, axial coding, and selective coding. In the open coding stage, the initial text of the interviews was coded and the concepts and categories were extracted subsequently. Contexts, processes, outcomes, and the relationship between research categories were formed In the central coding stage. Selective coding and creation of the final theory and model were performed after examining the categories and determining the relationship between them at different levels. In the quantitative part, the structural equation modeling method was used to study the relationships between model variables. Data analysis of the qualitative and quantitative data was performed using ATLAS.ti and AMOS software, respectively.

In this study, three common methods were used to achieve the reliability criterion of the findings. These included 1) validation and control by members: In this section, participants were asked to evaluate the overall findings and comment on their accuracy; 2) analytical comparisons: In this method, the structure of the theory was compared and evaluated with the raw data; 3) audit method: In this field, three experts in the field of grounded theory supervised the different stages of coding, conceptualization, and extraction of categories. The proposed methods of Lincoln and Goba with the criteria of validity, reliability, verifiability, and portability were used to increase the accuracy of the study. The researcher tried to increase the credibility of the study by long-term participation and sufficient interaction among the participants, the collection of valid information, and verification of the information by the participants. The reliability of data increased through step-by-step repetition, data collection and analysis, and review by experts. The approval of experts and their supplementary opinions were used to increase the verification criteria of the data. Data transfer capability was achieved by the evaluation of a rich description of the study report that could be applied in other areas. Other researchers will be able to understand the participants' similar experiences of marketing strategies and their comments.

\section{Results}

In the qualitative part of the present study, 3 $(18.7 \%)$ and $13(81.3 \%)$ individuals out of 16 experts and interviewees, were female and male, 
respectively, with a mean \pm SD age of $51.8 \pm 2.15$ years. Regarding the level of education, it should be noted that 4, 6, and 6 people had bachelor's, master's, and doctorate degrees, respectively. In the quantitative part, out of 210 people, 123 (58.5\%) and 87 (41.5\%) persons were male and female, respectively. The age range of 13 (6.1\%), 65 (30.9\%), 103 (49.0\%), and 29 $(0.14 \%)$ people were $25-29,30-34,35-40$, and 40 years and older. Regarding the level of education, 76 (36.1\%), 88 (41.9\%), and 46 (22.0\%) persons had a bachelor's, master's, and a doctorate's degree (Table 1).

\begin{tabular}{|c|c|c|c|c|c|c|}
\hline Variable & & & Frequency (\%) & Mean (SD) & Maximum & Minimum \\
\hline \multirow{7}{*}{$\begin{array}{l}\text { Qualitative } \\
\text { section }\end{array}$} & Age & & & $51.8(2.15)$ & 58 & 43 \\
\hline & Gender & Female & 3 & & & \\
\hline & & Male & 13 & & & \\
\hline & & $\mathrm{BSc}$ & 4 & & & \\
\hline & Education & MSc & 6 & & & \\
\hline & & $\mathrm{PhD}$ & 6 & & & \\
\hline & Job experience & & & $14.36(2.42)$ & 18 & 10 \\
\hline \multirow{9}{*}{$\begin{array}{l}\text { Quantitative } \\
\text { section }\end{array}$} & Condor & Female & 170 & & & \\
\hline & Genaer & Male & 203 & & & \\
\hline & & $25-29$ & 13 & & & \\
\hline & А бе бroun & $30-34$ & 65 & & & \\
\hline & Age group & $35-39$ & 103 & & & \\
\hline & & 40 years and older & 29 & & & \\
\hline & & $\mathrm{BSc}$ & 76 & & & \\
\hline & Education & MSc & 88 & & & \\
\hline & & $\mathrm{PhD}$ & 46 & & & \\
\hline
\end{tabular}

\begin{tabular}{|c|c|c|}
\hline Dimensions of the paradigm model & Category & Concept \\
\hline Axis/core phenomenon & $\begin{array}{l}\text { Evaluate the performance of } \\
\text { national accreditation of hospitals }\end{array}$ & $\begin{array}{l}\text { Systematic evaluation of hospital performance, detection, } \\
\text { and prioritization of hospital weaknesses, improving } \\
\text { hospital performance }\end{array}$ \\
\hline Casual condition & Recipient support & $\begin{array}{l}\text { Responding to complaints and suggestions, timely and } \\
\text { continuous access to the treatment team, providing } \\
\text { accommodation facilities, respectful behavior, and } \\
\text { providing the required information }\end{array}$ \\
\hline \multirow{4}{*}{$\begin{array}{l}\text { Strategic condition/ actions and } \\
\text { interactions }\end{array}$} & Competence of assessment teams & $\begin{array}{c}\text { Technical knowledge, communication skills, unity of } \\
\text { procedure, evaluation within the standards, qualitative } \\
\text { comments of the evaluators } \\
\text { Technical knowledge, communication skills, unity of }\end{array}$ \\
\hline & Accreditation executive structure & $\begin{array}{l}\text { Technical knowledge, communication skills, unity of } \\
\text { procedure, evaluation within the standards, qualitative } \\
\text { comments of the evaluators }\end{array}$ \\
\hline & Accreditation executive structure & $\begin{array}{c}\text { Time interval of changes, ranking criteria, the validity } \\
\text { period of certificates }\end{array}$ \\
\hline & $\begin{array}{l}\text { Comprehensive and barrier } \\
\text { standards }\end{array}$ & $\begin{array}{l}\text { Balance of structural, process and outcome standards, } \\
\text { standard attention to the diversity of hospital ownership, } \\
\text { standard attention to the diversity of hospital services, } \\
\text { transparency and comprehensibility of standards, the } \\
\text { enforceability of standards }\end{array}$ \\
\hline Context condition & Empowerment of process owners & Empowerment of managers, employees, and graduates \\
\hline \multirow{4}{*}{ Mediator Conditions } & $\begin{array}{l}\text { The proportion of hospital } \\
\text { resources to the implementation } \\
\text { of standards }\end{array}$ & $\begin{array}{l}\text { Proportionality of financial resources, adequacy of } \\
\text { equipment resources, adequacy of human resources }\end{array}$ \\
\hline & $\begin{array}{l}\text { Sharing accreditation benefits } \\
\text { with service providers }\end{array}$ & $\begin{array}{l}\text { Hospital income, job stability of managers, motivation of } \\
\text { physicians 'participation, motivation of employees' } \\
\text { participation }\end{array}$ \\
\hline & Participation of service producers & $\begin{array}{l}\text { Involvement of senior managers, involvement of middle } \\
\text { managers, involvement of physicians }\end{array}$ \\
\hline & Regulatory regulations & $\begin{array}{c}\text { The role of insurance organizations, the role of regulatory } \\
\text { laws }\end{array}$ \\
\hline \multirow{2}{*}{ Results } & Services quality & $\begin{array}{c}\text { Process improvement, access to appropriate equipment, } \\
\text { department/unit performance indicators, central } \\
\text { management program }\end{array}$ \\
\hline & Safety & $\begin{array}{c}\text { Prioritization of safety issues, safety indicators, } \\
\text { prevention and learning approach, occupational exposure } \\
\text { management }\end{array}$ \\
\hline
\end{tabular}


Out of 1,387 obtained codes from open coding, 44 concepts and 12 categories were identified through interviews and data analysis. Table 1 presents the main concepts and categories assigned to them. The identified categories were placed in the paradigm model based on the approach of Strauss and Corbin Foundation and were placed in each dimension of the paradigm model, including causal, contextual, and intervening conditions, as well as strategy and outcome. In the axial coding of the present study, the following categories were identified: national accreditation performance evaluation of hospitals, customer service support, competency of assessment teams, accreditation executive structure, comprehendsiveness and barrier standards, empowerment of process owners, matching hospital resources with implementation standards, sharing accreditation benefits with service providers, participation of service providers, monitoring regulations, and service quality and safety. In the domain of selective coding, the issue of evaluating the performance of national accreditation of hospitals was identified as a central category. Based on the grounded theory approach of the Strauss and Corbin Foundation, the obtained categories for presenting a paradigm model were arranged based on the central phenomenon, causal, and intervening, contextual conditions, as well as strategy and outcome.

The validity of the research questionnaire was confirmed by 14 experts who received a version of the questionnaire (a group of university professors, managers, and experts with more than 10 years of work experience). Studies were performed by calculating the content validity index and content validity ratio. The minimum acceptable value of content validity ratio and content validity index of the questionnaire were obtained at 0.51 and 0.79 by these experts, respectively. The obtained coefficients of Cronbach's alpha, composite reliability, and mean- variance indicated the good reliability of the identified variables (Table 3). Based on the data presented in Table 4, the standard factor coefficient of causal conditions in the axial phenomenon (evaluation of national accreditation performance of hospitals), $t$ value, and p-value were 0.65 and 7.121 , less than 0.05 , respectively. Therefore, from the perspective of the participants in the study, causal conditions were effective in evaluating the performance of national accreditation of hospitals. The standard coefficient of the variable of contextual conditions in the axial phenomenon (evaluation of national accreditation performance of hospitals), the t-value, and $p$-value were $0.66,7.687$, and less than 0.05 , respectively. Moreover, based on the participants in the study, the contextual conditions were effective in evaluating the performance of national accreditation of hospitals as well. The standard factor coefficient of the intervening condition in the axial phenomenon (evaluation of national accreditation performance of hospitals), the tvalue, and p-value were $0.85,12.176$, and less than 0.05 , respectively. The interventionist conditions were considered to be effective in evaluating the national accreditation performance of hospitals by the participants in the study. The standard coefficient of the variable of contextual conditions in the strategy, the $t$-value, and the p-value were $0.78,9.714$, and less than 0.05 , respectively. Furthermore, according to the participants in the study, the contextual conditions were effective in the adopted strategy. The standard factor coefficient of the variable strategy adopted in the outcome, the $t$-value, and the p-value were 0.62 , 6.244 , and less than 0.05 , respectively. From the perspective of the participants in the study, the selected strategy was effective on the outcome.

As can be seen in Table 5, the value of the chisquare statistic in the model, the degree of freedom of the model, and the result of their ratio were

Table 3. Reliability of research variables

\begin{tabular}{|c|c|c|c|}
\hline Variables & Chronbach's $\alpha$ & CR & AVE \\
\hline Recipient support & 0.780 & 0.873 & 0.754 \\
\hline Empowerment of process owners & 0.810 & 0.867 & 0.712 \\
\hline Evaluation of the performance of the national accreditation of the hospital & 0.787 & 0.746 & 0.762 \\
\hline The proportion of hospital resources to the implementation of standards & 0.760 & 0.871 & 0.827 \\
\hline Sharing accreditation benefits with service providers & 0.825 & 0.866 & 0.717 \\
\hline Participation of service producers & 0.753 & 0.911 & 0.832 \\
\hline Supervisory regulations & 0.731 & 0.781 & 0.689 \\
\hline Competence of the assessment team & 0.845 & 0.898 & 0.772 \\
\hline Accreditation executive structure & 0.732 & 0.764 & 0.669 \\
\hline Comprehensive and barrier standards & 0.873 & 0.829 & 0.728 \\
\hline Quality of service & 0.812 & 0.896 & 0.813 \\
\hline Safety & 0.803 & 0.723 & 0.721 \\
\hline
\end{tabular}

Table 4. Relationship among the variables of the paradigm model for evaluating the performance of national accreditation of hospitals

\begin{tabular}{lccc}
\hline Path & Standard Coefficient & t & P-value \\
\hline Casual $\rightarrow$ Axial & 0.65 & 7.121 & 0.000 \\
Context $\rightarrow$ Axial & 0.66 & 7.687 & 0.000 \\
Moderate $\rightarrow$ Axial & 0.85 & 12.176 & 0.000 \\
Context $\rightarrow$ Strategy & 0.78 & 9.714 & 0.000 \\
Strategy $\rightarrow$ Result & 0.62 & 6.244 & 0.000 \\
\hline
\end{tabular}




\begin{tabular}{lccc}
\hline \multicolumn{2}{l}{ Table 5. Fit indicators of the proposed research model } & \\
\hline Index & Desirable value & Value in current research & Status \\
\hline$\chi^{2}$ & - & 4599.861 & - \\
$\mathrm{P}-$ value & - & 0.000 & Verified \\
$\mathrm{df}$ & $0 \leq \mathrm{df}$ & 2421 & Verified \\
$\chi^{2} / \mathrm{df}$ & $\chi^{2} / \mathrm{df}<3$ & 1.899 & Verified \\
RMSEA & $<0.08$ & 0.061 & Verified \\
NFI & $0.8<$ & 0.713 & Not verified \\
AGFI & $0.8<$ & 0.759 & Not verified \\
GFI & $0.8<$ & 0.899 & Verified \\
CFI & $0.8<$ & 0.901 & Verified \\
IFI & $0.8<$ & 0.842 & Verified \\
SRMR & Closer to 0 & 0.1151 & Verified \\
\hline
\end{tabular}

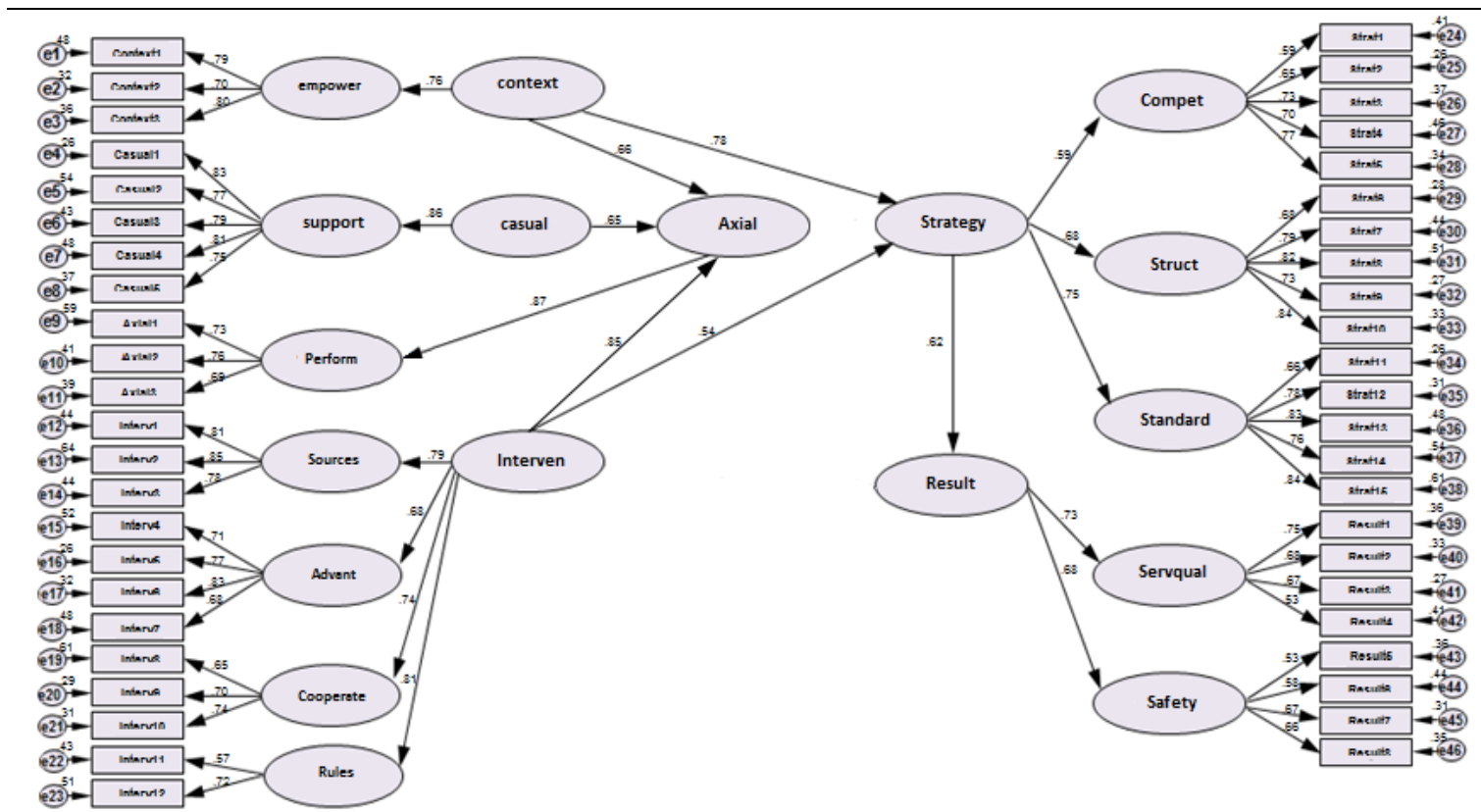

Chi_square $=4599.861 ; D F=2421 ; P-V A L U E=.000 ; G F I=.899 ; C F I=.901 ; R M S E A=.061$

Figure 1. The proposed model with standard coefficients

4599.861, 2421, 1.899, respectively, which were acceptable values. On the other hand, the fit indices of the main model, such as CFI and IFI were all in the acceptable range and the SRMR index was estimated at 0.1151 .

\section{Discussion}

This study aimed to present and validate the performance evaluation model of the national accreditation scheme of hospitals. Accordingly, the grounded theory method was adopted to identify the dimensions of the model. The identified dimensions included central phenomenon, causal, contextual, and intervening conditions, as well as strategy and results. The validation of the model indicated that the introduced model had good validity and reliability. Moreover, the model had good fit indices. The results showed that the category of support of the recipient as a causal condition has a significant effect on the evaluation of the national accreditation scheme in hospitals. In other words, support for the recipient of the service requires an evaluation of national accreditation models in hospitals. Ramezani et al. conducted a study to support the rights of service recipients by health care providers through the development of accreditation standards. They found that the hospital accreditation scheme as an external evaluation model is a good method that ensures the observance of the rights of service recipients by providing standards for the establishment of a comprehensive and systematic management system in hospitals that promote a patient-centered culture in a safe environment (17). The results of a study conducted by Mossadeghrad et al. entitled "Evaluation of the effects of accreditation in hospitals" indicated that accreditation of hospitals has a significant effect on service recipients. Therefore, the accreditation evaluation program of hospitals plays an effective role in the improvement of patients' safety and respect for patients' rights and has led to the reduction of nosocomial infections and 
patients mortality. They also mentioned the role of accreditation in the recruitment of service recipients as one of its prominent features and reported an inverse relationship between the number of hospital beds and the results of accreditation (2). The results of a study performed by Mohebbifar et al. showed that there was a negative relationship between accreditation and patient satisfaction. In other words, patients' satisfaction decreased with the increase of the accreditation score of hospitals, which was inconsistent with the results of the present study (18). A study carried out by Holger Eilers et al. on the attitudes of hospital staff toward accreditation in Denmark showed that the general attitude of service recipients toward the implementation of the hospital accreditation scheme was of particular importance. They also noted the attitude of service providers and found that it is also important in the accreditation process. In their view, attitudes may be a reflection of political orientations and prevent the adoption of accreditation agendas (19). However, according to a study conducted by Al-Masabi et al. on the subject of a systematic review of the relationship between health care accreditation and patients satisfaction in 2014, no significant relationship was observed between accreditation system and patient support. This is probably because accreditation standards focus primarily on the structure and treatment processes rather than outcome indicators; therefore, its objectives are not very tangible to patients (20). Sack et al. (2011) in a study that investigated the relationship between hospital accreditation and patient satisfaction with hospital services concluded that there was no significant relationship between hospital accreditation and patient support. Moreover, many hospital accreditation systems are designed with a focus on the patient; however, the researchers did not observe a significant relationship between the two (8).

The present study showed that the category of empowerment of process owners as a background condition has a significant effect on the evaluation of the national accreditation performance of hospitals. A study carried out by Ghadami et al. (2018) on the factors affecting the method of scoring hospital accreditation in Iran showed that the empowerment of evaluators played a significant role in evaluating the accreditation model (21). Me'raji study on the challenges and strengths of the implementation of the accreditation process from the perspective of health information management staff in 2016 showed that some benefits of the implementation of accreditation model included the effective management and guidance, awareness about the objectives of the accreditation system, dynamism, and efficiency, creation of motivation for the employees through rewards and participation in the accreditation program. However, increase in the staff workload and division of tasks, lack of training in quality improvement methods, insufficient information of the staff about the progress of their work, lack of budget allocation, lack of staff motivation, and lack of teamwork are among the challenges of implementation of the accreditation system (22).

The results of the present study showed that the intervening conditions that significantly affect the evaluation of the accreditation performance of hospitals include improvement of hospital resources through the implementation of standards and supervisory regulations, sharing accreditation benefits with service providers, and participation of service providers in the program. The results of the study performed by Kikavousi Arani et al. on the development of national accreditation standards for management and leadership units in Iranian hospitals in 2014 revealed that hospital managers can play an important role in establishing accreditation standards through the implementation of accreditation standards for the hospital management and leadership unit. Clinical and nonclinical hospital units/wards provide patients' safety and improve quality (23). The study carried out by Mossadeghrad and Shahebrahimi (2018) on the subject of the relationship between accreditation and performance of hospitals showed that the axes of management and leadership, emergency and procurement management had an effective role in the accreditation of hospitals' performance (24). Fotouhi et al. pointed out that effective evaluation of hospital accreditation can be achieved through the elimination of deficiencies in the structural resources of hospitals and efforts to attract higher participation of the physicians (25). Moradi et al. in their study pointed out the allocation of appropriate budgets for effective implementation of accreditation scheme (6).

Based on the obtained results, strategic factors such as the competence of the assessment teams, the executive structure and comprehensiveness of the accreditation scheme, and the establishment of standards have a significant effect on the quality of services and safety of the hospital. Jafari Pouyan et al. (2018) found that the acceptance of accreditation by evaluators, the spirit of teaching, and efforts to develop knowledge and skills can affect the implementation of an effective hospital accreditation program positively (26). Anders et al. in a study entitled "whether hospital accreditation can enhance the patient experience?" published the long-term evidence from Hong Kong Hospital in 2019. They concluded that although hospital accreditation has not been shown to improve patient outcomes, it may improve the patient's experience. In addition, quality improvement initiatives related to accreditation may address areas of concern highlighted by Hong Kong patients, including the participation of providers in care and emotional support (27). In the examination of the accreditation status of hospitals in Indonesia in 2019, Wardhani et al. concluded that higher-level, 
government-run hospitals are more likely to be valid regardless of the expertise and intensity of market competition. They believed that the executive structure of the accreditation system plays a significant role in evaluating the accreditation of hospitals (28). Curia et al., in developing a model for measuring the accreditation system of Brazilian hospitals in 2019, found that leadership, staff management, quality management, organizational culture, process orientation, and safety are strongly related to the development of health organizations and can directly affect the accreditation process (29). In 2011, Al-Khanizan et al. conducted a study on the impact of accreditation on the quality of health services and found that accreditation programs improve output indicators and clinical conditions, as well as specific accreditation programs that have a positive effect on specialized clinical processes.

\section{Conclusion}

They concluded that there was strong evidence that the accreditation program promoted health care processes and that the accreditation systems should be supported as a means of quality improvement (30).

\section{Acknowledgments}

The authors would like to thank all participants in this study for their cooperation.

\section{Footnotes}

Conflicts of Interest: The authors declare that they have no conflict of interest regarding the publication of the present study.

Authors' Contribution: SPP and LN designed the research approach and methodology. SPP gathered data and wrote the article. IR analyzed the data. LN and IR reviewed the article.

Ethical Approval: The study protocol was approved by the Ethics Committee in Biomedical Research Center of Islamic Azad University in Semnan, Iran (IR.IAU.SEMNAN.REC.1398.020).

Informed Consent: All the participants were informed about the objectives of the study, and participation in this study was based on willingness.

Funding/Support: This study was not funded by any institute or organization in the public or private sector.

\section{References}

1. Mardani S, Tabibi SJ, Riahi L. Relationship between safety and staff performance in hospital. Int J Hosp Res. 2013;2(4):205-14.

2. Mosadeghrad AM, Akbari Sari A, Yousefinezhadi T. Evaluation of accreditation effects in hospitals. Tehran Univ Med J. 2019;76(12):804-12.

3. Braithwaite J, Greenfield D, Westbrook J, Pawsey M, Westbrook M, Gibberd R, et al. Health service accreditation as a predictor of clinical and organisational performance: a blinded, random, stratified study. Qual Saf Health Care. 2010;19(1):14-21. doi: 10.1136/qshc.2009.033928. [PubMed: 20172877].

4. Amerioon A, Tofighi S, Mahdavi S, Mamghani H, Mesgarpour Amiri M. Evaluation of JOC accreditation standard in a military hospital lab. Mil Med J. 2011;13(2):76-7.

5. Brubakk K, Vist GE, Bukholm G, Barach P, Tjomsland O. A systematic review of hospital accreditation: the challenges of measuring complex intervention effects. BMC Health Serv Res. 2015;15(1):280. doi: 10.1186/s12913-015-0933-x. [PubMed: 26202068].

6. Moradi R, Nemati A, Bahman ZN, Shokri A, Mohammadi M, Soltantajiyan A. Effect of accreditation on the health services delivering in university hospitals of Isfahan. J Healthcare Manag. 2015;6(3):67-76.

7. Azami-Aghdash S, Bazargani HS, Ghasemi B, Mirzaei A, Aghaie $\mathrm{MH}$. The existing barriers and infrastructures to implement accreditation from the perspective of hospitals' managers in East Azerbaijan Hospitals: a mixed method study. Depiction Health. 2013;4(2):35-42.

8. Sack C, Scherag A, Lütkes P, Günther W, Jöckel KH, Holtmann G. Is there an association between hospital accreditation and patient satisfaction with hospital care? A survey of 37000 patients treated by 73 hospitals. Int J Qual Health Care. 2011;23(3):278-83. doi: 10.1093/intqhc/mzr011. [PubMed: 21515636].

9. Heuer AJ. Hospital accreditation and patient satisfaction: testing the relationship. J Healthcare Qual. 2004;26(1):46-51. doi: 10.1111/j.1945-1474.2004.tb00471.x. [PubMed: 14763320].

10. Fong J, Marsh GM, Stokan LA, Sang W, Vinson C, Ruhl L. Hospital quality performance report: an application of composite scoring. Am J Med Qual. 2008;23(4):287-95. doi: 10.1177/1062860608317064. [PubMed: 18658102].

11. Buetow S, Wellingham J. Accreditation of general practices: challenges and lessons. Qual Saf Health Care. 2003;12(2):12935. doi: 10.1136/qhc.12.2.129. [PubMed: 12679510].

12. Sadeghi T, Gholamhoseinni N, Khoshab H, Karami M, Nouhi E, Sabzevari S. Assessment managers' and hospital staff knowledge and attitude to accreditation. Quart J Nurs Manag. 2016;5(2):9-17. doi: 10.29252/ijnv.5.2.9.

13. Tabrizi JS, Azami-Aghdash S, Abdollahi L, Daemi A, Fard KY, Valizadeh S, et al. Required infrastructures to implement accreditation in iran: the perspective of top managers of the teaching hospitals in Tabriz and Ardabil university of medical sciences. Depiction Health. 2013;4(2):29-34.

14. Salmon JW, Heavens J, Lombard C, Tavrow P. Quality assurance project, the impact of accreditation on the quality of hospital care: KwaZulu-Natal Province, Republic of South Africa. Available at: URL: www.ihffih.org/Resources/AccreditationQuality-in-hospitals/Quality-assurance-project-the-impact-ofaccreditation-onthe-quality-of-hospital-care-Kwazulu-Natalprovince-Republic-of-South-Africa; 2003.

15. Greenfield D, Pawsey M, Naylor J, Braithwaite J. Are accreditation surveys reliable? Int J Health Care Qual Assur. 2009;22(2):105-16. doi: 10.1108/09526860910944601. [PubMed: 19536962].

16. Arab M, Zarei A, Hosseini M. Awareness and observation of patients' rights from the perspective of patients: a study in university hospitals in Tehran. J Sch Public Health Institute Public Health Res. 2010;8(2):77-86.

17. Ramezani M, Arani LK, Abedini P. Accreditation standards of patient rights in Iranian hospital. J Med Ethics. 2010; 3(10):103-25.

18. Mohebbifar R, Rafiei S, Asl AM, Ranjbar M, Khodayvandi M. Association between hospital accreditation and patient satisfaction: a survey in the western province of Iran. Bangladesh J Med Sci. 2017;16(1):77-84.

19. Ehlers LH, Jensen MB, Simonsen KB, Rasmussen GS, Braithwaite J. Attitudes towards accreditation among hospital employees in Denmark: a cross-sectional survey. Int J Qual Health Care. 2017;29(5):693-8. doi: 10.1093/intqhc/mzx090. [PubMed: 28992155].

20. Almasabi M, Yang H, Thomas S. A systematic review of the association between healthcare accreditation and patient 
satisfaction. World Appl Sci J. 2014;31(9):1618-23. doi: 10.5829/idosi.wasj.2014.31.09.83322.

21. Ghadami L, Masoudi Asl Y, Modiri M, Hesam S. The survey of effective factors on hospital accreditation scoring method in Iran. J Healthcare Manag. 2018;9(1):47-60.

22. Mahmoodian S, Safaei F, Meraji M, Kimiafar K, Farsinegar N, Ghasemi R. Challenges and strengths of implementing accreditation process from health information management staff perspective. J Paramed Sci Rehabil. 2016;5(2):25-33.

23. Keikavoosi Arani L, Ramezani M, AbedinSalimAbadi P. Codification of national accreditation standards for management and leadership in hospitals of Iran. J Mazandaran Univ Med Sci. 2014;24(119):194-8.

24. Mosadeghrad AM, Shahebrahimi SS, Ghazanfari M. Exploring the relationship between accreditation and hospital performance: using data mining approach. J Sch Public Health Institute Public Health Res. 2018;16(1):33-50.

25. Fotuhi MA, Khoshgoftar A, Bakhshande H, Karami G, Rasti Broujeni M. Evaluation of viewpoint of executive management team of hospitals of Qom province in terms of the third generation of hospital accreditation standards, 2017, (Iran). Qom Univ Med Sci J. 2018;12(5):62-70.
26. Jaafaripooyan E, Mosadeghrad AM, Salarvand A. Hospital accreditation surveyors' evaluation criteria in Iran. Payavard Salamat. 2019;13(2):110-22.

27. Andres EB, Song W, Song W, Johnston JM. Can hospital accreditation enhance patient experience? Longitudinal evidence from a Hong Kong hospital patient experience survey. BMC Health Serv Res. 2019;19(1):623. doi: 10.1186/s12913019-4452-z. [PubMed: 31481058].

28. Wardhani V, van Dijk JP, Utarini A. Hospitals accreditation status in Indonesia: associated with hospital characteristics, market competition intensity, and hospital performance? BMC Health Serv Res. 2019;19(1):372. doi: 10.1186/s12913-0194187-x. [PubMed: 31185984].

29. Corrêa JÉ, Turrioni JB, Mello CH, Santos AC, Da Silva CE, De Almeida FA. Development of a system measurement model of the Brazilian hospital accreditation system. Int J Environ Res Public Health. 2018;15(11):2520. doi: 10.3390/ijerph15112520. [PubMed: 30423866].

30. Alkhenizan A, Shaw C. Impact of accreditation on the quality of healthcare services: a systematic review of the literature. Ann Saudi Med. 2011;31(4):407-16. doi: 10.4103/02564947.83204. [PubMed: 21808119]. 